\title{
Development of integrated thematic teaching material used discovery learning model in grade $\mathrm{V}$ elementary school Pengembangan bahan ajar tematik terpadu menggunakan model Discovery Learning di kelas V sekolah dasar
}

\author{
Desyandri Desyandri ${ }^{1}$, Muhammadi Muhammadi ${ }^{2}$, Mansurdin Mansurdin ${ }^{3}$, Rijal Fahmi $^{4}$ \\ ${ }^{1234}$ Universitas Negeri Padang, Indonesia
}

\section{Article Info \\ Article history:}

Received Desember $12^{\text {th }}, 2018$

Revised April 02 ${ }^{\text {th }}, 2019$

Accepted May $13^{\text {th }}, 2019$

\section{Keyword:}

Developing

Integrated

Thematic

Learning material

Discovery learning

\begin{abstract}
This research is intends develop integrated thematic learning materials by using discovery learning (DL) model in the 5th grade of elementary school. It categorize this research into research and development study. The model includes four phases, defining, designing, developing, and disseminating phases. However, it did not include the disseminating phases. The subjects of the research were 5 th grade students. The results of the research show that the validity score of the learning materials developed is 3,36. Questionnaire and interviews with the teachers and the students reveal that the materials developed are practical. The score given by the teachers is $96,43 \%$, and by the students is $84,5 \%$. Based on the results, we conclude it that the integrated thematic learning materials developed by using (DL) model are valid and practical to be use in the learning process.
\end{abstract}

2019 The Authors. Published by Indonesian Institute for Counseling,

Education and Therapy (IICET). This is an open access article under the CC BY license (https://creativecommons.org/licenses/by/4.0/)

\section{Corresponding Author:}

Desyandri Desyandri,

Email: desyandri@fip.unp.ac.id

\section{Pendahuluan}

Pendidikan sebagai salah satu investasi masa depan, tidak akan berarti apa-apa jika tidakdibarengi dengan senantiasa melakukan peningkatan, pengembangan, dan inovasi pembelajaran yang berkelanjutan(Barrett, Gaskins, \& Haug, 2019; Bequette, Cardiel, Cohn, Kollmann, \& Lawrenz, 2019; Lenk, Glinka, \& Hesse, 2019). Salah satu upaya untuk mencapai tujuan tersebut adalah selalu mencarikan dan menemukan terobosan-terobosan baru atau inovasi dalam proses pembelajaran yang berdampak pada penanaman nilai-nilai karakter dan budaya bangsa (Desyandri, 2017). Pada revolusi industri 4.0 dalam bidang pendidikan dan pembelajaran di Indonesia diberlakukan kurikulum baru, yaitu kurikulum 2013 oleh Kementerian Pendidikan dan Kebudayaan. Beberapa mata pelajaran mengalami penggabungan, karena mempengaruhi jumlah jam mengajar walaupun disisi lain juga terdapat mata pelajaran yang mendapat tambahan jam, hal ini menjadi kurang efektif, padahal kurikulum merupakan unsur penting dalam pelaksanaan pendidikan di sekolah. Kurikulum 2013 merupakan kurikulum yang dikembangkan dari Kurikulum Tingkat Satuan Pendidikan (KTSP).

Kurikulum 2013 menggunakan pendekatan tematik terpadu yang merupakan suatu pendekatan dalam pembelajaran yang secara sengaja mengaitkan beberapa aspek baik dalam intra pembelajaran ataupun antar mata pelajaran(Saputri, 2017; Sukerti, Marhaeni, \& Suarni, 2015). Kurikulum 2013 menggunakan pendekatan tematik terpadu memiliki buku siswa dan buku guru Penggunaan bahan ajar merupakan salah satu faktor keberhasilan proses pembelajaran. Bahan ajar yang digunakan harus sesuai dengan kriteria sehingga akan melahirkan pembelajaran yang efektif serta menyenangkan(Kobayashi, 2019; Kung, 2019; Priatna, Martadipura, \& Lorenzia, 2019). 
Secara umum pelaksanaan pembelajaran tematik terpadu pada kurikulum 2013 belum berjalan optimal. Masih ditemukan beberapa permasalahan, seperti pelaksanaan pembelajaran yang masih berpusat pada guru.(Hernawan, 2009; Machali, 2014). Kondisi ini memperlihatkan bahwa pembelajaran yang dilakukan guru secarakeseluruhan belum maksimal dan proses pembelajaran masih menggunakan pendekatan pembelajaran konvensional yang didominasi oleh ceramah(Desyandri, 2012). Hal senada juga ditemukan dalam hasil penelitian, yakni pembelajaran masih berpusat pada guru, kurangnya kesempatan siswa memperoleh pengalaman langsung baik mengamati, menanya, mencobakan, mengolah informasi, dan mengkomunikasikan, monoton, sebagian siswa belum aktif selama proses pembelajaran, dan pembelajaran yang diberikan guru lebih didominasi ceramah (Desyandri; Vernanda, 2017). Kondisi ini bertolak belakang dengan peran guru pada abad 21, yakni: "Teachers play a significant role in helping students develop 21st century skills by applying methods that increase student's abilities" (Alismail \& McGuire, 2015). Guru harus memiliki upaya kreatif dan inovatif, serta menyiapkan strategi pembelajaran modern, memanfaatkan teknologi, sehingga meningkatkan parsisipasi siswa dalam pembelajaran(Cheng, 2018; Malsbary, 2018; Teplykh, Akhmetzyanova, \& Bashirova, 2019).

Kondisi tersebut juga tergambar pada hasil pengamatan/observasi langsung ke SD Negeri 15 Ulu Gadut mulai tanggal 4, 5 dan 7 Oktober 2016, bahan ajar yang digunakan oleh guru masih ada materi yang disajikan dari yang sulit ke yang mudah, dan dalam proses pembelajaran guru masih sangat kurang memberikan motivasi belajar kepada siswa. Hal ini kurang sesuai dengan prinsip pengembangan bahan ajar, menurut Daryanto dan Dwicahyono (2014: 172) menyatakan bahwa "Prinsip pengembangan bahan ajar di antaranya bahan ajar yang di sajikan mulai dari yang mudah untuk memahami yang sulit, dari yang konkret untuk memahami yang abstrak, dan motivasi belajar yang tinggi merupakan salah satu faktor penentu keberhasilan belajar". Selanjutnya gambar, perkataan, kutipan, dalam bahan ajar yang digunakan oleh guru masih belum menumbuhkan rasa ingin tahu siswa dan keaktifan siswa, bahan ajar yang digunakan oleh guru belum memiliki kecukupan materi untuk memahami dan melakukan KD yang di belajarkan. Ini tentu kurang sesuai dengan prinsip pengembangan bahan ajar, menurut Kurniasih dan Sani (2014: 141) "Prinsip pengembangan bahan ajar diantaranya gambar, perkataan, kutipan, menumbuhkan rasa ingintahu siswa dan keaktifan siswa (menemukan), bahan ajar harus memiliki kecukupan materi untuk memahami dan melalukan KD".

Seterusnya bahan ajar yang digunakan oleh guru dan siswa masih kurang menimbulkan siswa untuk aktif, masih kurang menarik dan menyenangkan, masih kurang holistik, dan Autentik. Hal ini juga kurang sesuai dengan karakteristik bahan ajar, menurut prastowo (2014: 142) bahan ajar memiliki beberapa karakteristik diantaranya:"(1) aktif; (2) menarik atau menyenangkan; (3) holistik; dan (4) autentik (memberikan pengalaman langsung)".

Mengatasi masalah yang dikemukakan di atas perlu dilakukan pengembangan bahan ajar yang efektif dan kreatif yang menggunakan model yang tepat. Model yang dapat digunakan adalah model Discovery Learning (DL). Menurut Riyanto (2010:138) model Discovery Learning adalah "Belajar mencari dan menemukan sendiri, dalam pembelajarannya siswa diberi peluang untuk mencari, memecahkan, hingga menemukan cara-cara penyelesaiannya dan jawaban-jawabannya sendiri". Senada dengan itu, Menurut Faisal (2014:102) model Discovery Learning adalah "model pembelajaran yang mendefinisikan sebagai proses pembelajaran yang terjadi bila siswa tidak disajikan dalam bentuk finalnya, tetapi diharapkan mengorganisasikan sendiri". Hal ini menggambarkan bahwa model Discovery Learning didefinisikan sebagai proses pembelajaran yang disajikan tidak dalam bentuk finalnya, tetapi diharapkan mengorganisasi sendiri(Amiyani \& Widjajanti, 2019; Capuano \& Toti, 2019; Syarafina \& Mahmudi, 2019).

\section{Metode}

Jenis penelitian yang digunakan dalam penelitian ini adalah penelitian pengembangan. Penelitian pengembangan merupakan penyederhanaan istilah dari penelitian dan pengembangan atau Research and Development (R\&D). Penelitian dan pengembangan ini salah satunya bertujuan untuk menghasilkan sebuah produk yang efektif, hal ini sejalan menurut Gay (dalam Emzir, 2011:263) mengemukakan tujuan penelitian dan pengembangan adalah "Bukan untuk merumuskan atau menguji teori, tetapi untuk mengembangkan produk-produk yang efektif untuk digunakan di sekolah-sekolah".

Uji coba produk dilakukan pada subjek uji coba yang telah dipilih berdasarkan pertimbangan tertentu. $\mathrm{Hal}$ ini bertujuan agar penggunaan Bahan ajar tematik terpadu yang telah dikembangkan berjalan dengan baik. Subjek uji coba pada penelitian ini adalah siswa kelas V SD Negeri 15 Ulu Gadut Kecamatan Pauh. Prosedur pengembangan melakukan Tahap studi pendahuluan yang merupakan kegiatan mencari dan 
mengumpulkan informasi. Setelah melakukan studi pendahuluan di lanjutkan dengan desain model. Model pengembangan yang digunakan dalam penelitian ini merujuk pada Thagarajan (1974). Thagarajan melakukan 4 tahap dalam penelitian yaitu define (pendefinisian), design (perancangan), develop (perngembangan), dan disseminate (penyebaran). Tetapi peneliti melakukan tidak sampai pada tahap disseminate karena keterbatasan peneliti dari berbagai hal baik segi tenaga, waktu dan biaya, maka tahap penyebaran (disseminate) tidak peneliti lakukan.

Bahan ajar tematik terpadu yang sudah dikembangkan diujicobakan pada siswa kelas V SD Negeri 15 Ulu Gadut hanya sampai pada tahap praktikalitas bukan efektifitas atau tahap penyebaran skala kecil/terbatas. Teknih pengumpulan data yang dilakukan yaitu; Uji Validitas Bahan Ajar dan Uji Praktikalitas Bahan Ajar.

\section{Hasil dan Pembahasan}

Hasil uji validasi bahan ajar yang dikembangkan dilanjutkan dengan kegiatan validasi oleh para ahli sesuai dengan bidang kajiannya yang terdiri dari 3 orang validator ahli. Berdasarkan hasil rekapitulasi bahan ajar yang sudah di validasi oleh validator. Bahan ajar di nyatakan valid dengan rata-rata keseluruhan 3,36.

Hasil Uji Praktikalitas Bahan Ajar yang yang telah dikembangkan dinyatakan valid, langkah selanjutnya adalah melakukan ujicoba untuk mengetahui praktikalitas bahan ajar. Uji coba dilakukan pada siswa kelas VC SD Negeri 15 Ulu Gadut Kecamatan Pauh berjumlah 25 siswa. Pelaksanaan uji coba telah dilakukan pada hari senin dan selasa tanggal 10-11 April 2017. Praktikalitas bahan ajar yang dikembangkan dapat dilihat dari hasil analisis angket praktikalitas oleh guru dan siswa dan hasil wawancara secara langsung dengan guru dan siswa setelah pembelajaran selesai. Hasil angket respon guru terhadap praktikalitas bahan ajar tematik terpadu menggunakan model discovery learning di dapatkan nilai persentase kepraktisannya adalah 96,43 \% termasuk dalam kategori sangat praktis. Hasil angket respon siswa terhadap praktikalitas bahan ajar tematik terpadu menggunakan model discovery learning menunjukkan nilai kepraktisan yang berada pada rentang $77 \%$ s/d $95 \%$ yang termasuk dalam kategori praktis dan sangat praktis. Hasil kepraktisan dari angket respon siswa secara keseluruhan adalah 84,5\% dengan kategori praktis. Kemudian berdasarkan hasil wawancara dengan guru dan siswa bahan ajar mudah digunakan oleh siswa dan sudah membantu siswa dalam pembelajaran.

Pengembangan bahan ajar tematik terpadu menggunakan model Discovery Learning dengan menggunakan model pengembangan yang merujuk pada Thagarajan (1974). Thagarajan melakukan 4 tahap dalam penelitian yaitu define (pendefinisian), design (perancangan), develop (perngembangan), dan disseminate (penyebaran). Penelitian pengembangan bahan ajar telah berhasil dilaksanakan dengan baik. Bahan ajar tersebut diujicobakan di kelas VC SD Negeri 15 Ulu Gadut Kecamatan Pauh dengan jumlah siswa 25 orang siswa. Hasil penelitian pengembangan yang telah dilakukan akan diuraikan lebih lanjut yang berkaitan dengan validitas dan praktikalitas bahan ajar yang dikembangkan. Hasil penelitian pengembangan yang telah dilakukan akan diuraikan lebih lanjut yang berkaitan dengan validitas dan praktikalitas bahan ajar yang dikembangkan. Untuk lebih jelasnya akan diuraikan sebagai berikut:

\section{Hasil validasi bahan ajar}

Sebelum bahan ajar diujicobakan pada siswa, bahan ajar harus divalidasi. Hal ini sejalan dengan pendapat Emzir (2011:273) bahwa sebelum diuji coba bahan ajar harus di validasi. Bahan ajar dikatakan valid apabila memenuhi kriteria tertentu. Plom (2007:121) menjelaskan bahwa karakteristik produk yang dikatakn valid adalah apabila ia merefleksi jiwa pengetahuan (state-of-art knowledge). Kemudian Menurut Scarvia B dan Anderson (dalam Suharsimi, 2009:65) menjelaskan bahwa, "A test is valid if it measures what it purpose to measure". Artinya sebuah tes dikatakan valid apabila tes tersebut dapat mengukur apa yang hendak diukur. Inilah yang disebut sebagai validasi isi. Sedangkan komponen-komponen produk tersebut harus konsisten atau sama lain disebut sebagai validasi konstruk. Artinya syarat suatu produk dikatakan valid jika memnuhi kriteria kevalidan isi dan konstruk. Berdasarkan analisis data penilaian validasi dari validator, maka validitas bahan ajar yang dikembangkan dinyatakan valid.

Beberapa aspek validitas bahan ajar yang dilakukan yaitu pada aspek kelayakan isi, aspek kebahsaan, aspek penyajian, aspek kegrafikan, serta aspek langkah-langkah model Discovery Learning (DL). Hasil validasi ditinjau dari kelayakan isi diperoleh nilai rata-rata 3,50 dengan kategori sangat valid. Ini berarti bahwa bahan ajar yang dikembangkan telah mengandung isi yang berkesinambungan dengan $\mathrm{KI}, \mathrm{KD}$, materi, dan bahan ajar sesuai dengan karateristik siswa. Bahan ajar juga sudah dapat menambah wawasan siswa dan sesuai dengan nilai-nilai moral dan sosial. Hal ini sesuai menurut Nurdin (2016:107) menjelaskan 
bahwa "Bahan ajar atau materi pembelajaran perlu dipilih dengan tepat agar seoptimal mungkin membantu siswa dalam mencapai Standar Kompentensi dan Kompetensi Dasar.

Hasil validasi pada aspek kebahasaan diperoleh nilai rata-rata 3,25 dengan kategori valid. Artinya bahasa yang digunakan pada bahan ajar telah sesuai dengan kaidah bahasa indonesia yang baik dan benar serta mudah dipahami. Hasil ini diperoleh setelah dilakukan perbaikan pada bahan ajar terkait penggunaan kalimat yang efektif dan penggunaan bahasa yang disesuaikan dengan tingkat perkembangan siswa. Menurut muslich (2010:303) menyatakan bahwa "Salah satu indikator kelayakan bahasa adalah pemakaian bahasa yang komunikatif”. Kemudian dari apek penyajian, bahan ajar yang dikembangkan sudah memenuhi urutan sajian yang sistematis dan menarik. Selain itu, bahan ajar juga dapat memberikan motivasi, interkasi, dan informasi yang menarik kepada siswa. Hal tersebut sesuai dengan karakteristik bahan ajar tematik yang kedua menurut Prastowo (2014:143) yaitu "menarik atau menyenangkan artinya bahan ajar memiliki sifat mempesona, merangsang, nyaman dilihat, dan banyak kemanfaatannya sehingga siswa senantiasa terdorong untuk terus belajar dan belajar darinya, bahkan siswa sampai terlihat asyik dengan bahan ajar tersebut sampai lupa waktu, karena penuh tantangan yang memacu andrenalin siswa. Hal ini terlihat dari hasil validasi yang diperoleh nilai rata-rata 3,27 yang tergolong kedalam kategori valid.

Ditinjau dari aspek kegrafikan, diperoleh hasil validasi dengan rata-rata 3,24 yang termasuk kedalam kategori valid. Ini menunjukkan bahwa bahan dapat terbaca dengan jelas, baik untuk kata letak, dan penggunaan gambar serta desain yang menarik. Pada awalnya menurut validator terdapat beberapa penggunaan warna yang kurang cocok dan serasi. Berdasarkan masukan dari validator dilakukan beberapa revisi berkaitan dengan hal tersebut. Sehingga pada akhirnya di dapat penyajian bahan ajar yang valid berdasarkan aspek kegrafikan. Kemudian dari langkah-langkah model Discovery Learning (DL), diperoleh rata-rata 3,45 yang termasuk kedalam kategori valid. Ini berarti bahan ajar yang dikembangkan sudah sesuai dengan model Discovery Learning (DL) yaitu bahan ajar dapat menstimulus siswa juga memuatkan masalah yang dipecahkan, bahan ajar sudah memuat data-data yang membantu dalam menyelesaikan masalah, bahan ajar sudah membantu siswa dalam penyimpulan dari penyelesaian masalah yang terlihat pada langkah-langkah kerja dan kegiatan yang terdapat dalam bahan ajar. Hal ini sesuai menurut Hosnan (2014:282) mengemukakan bahwa, "pembelajaran discovery learning adalah suatu model untuk mengembangkan cara belajar siswa aktif dengan menemukan sendiri, menyelidiki sendiri, maka hasil yang diperoleh akan setia dan tahan lama dalam ingatan, tidak akan mudah diupakan siswa".

Selanjut berdasarkan hasil rekapitulasi validasi bahan ajar oleh validator secara keseluruhan adalah 84,01 dengan rata-rata keseluruhan 3,36 dengan kategori valid. Kemudian berdasarkan hasil jumlah keseluruhan masing-masing validator didapatkan hasil yaitu, validator 1 dengan jumlah keseluruhan 89 dengan rata-rata keseluruhan 3,56 dengan kategori sangat valid, validator 2 dengan keseluruhan jumlah 74 dengan rata-rata keseluruhan 2,96 dengan kategori kurang valid dan validator 3 dengan jumlah keseluruhan 89 dengan ratarata keseluruhan 3,56 dengan kategori sangat valid. Berdasarkan hasil data validasi oleh vaidator dapat disimpulkan bahwa bahan ajar sudah layak digunakan dalam pembelajaran.

\section{Hasil uji praktikalitas bahan ajar}

Bahan ajar yang dikembangkan dikatakan praktis apabila bahan ajar yang dikembangkan dapat memudahkan guru dalam mengajar dan mudah dipahami oleh siswa. Sebagaimana yang dikemukakan oleh Suharsimi (2009:62) bahwa "Praktikalitas bersifat praktis adalah mudah dilaksanakan, mudah pemeriksaannya, dan dilengkapi oleh petunjuk-petunjuk yang jelas sehingga memudahkan guru dan siswa dalam pemakaian bahan ajar yang digunakan". Untuk melihat apakah praktis bahan ajar yang dikembangkan, bahan ajar di ujicobakan pada siswa dan guru kelas VA SD Negeri 15 Ulu Gadut Kecamatan Pauh. Untuk lebih jelasnya dapat dilihat penjabarannya sebagai berikut.

\section{Hasil analisis data respon guru terhadap bahan ajar}

Hasil jawaban guru tentang bajan ajar yang digunakan adalah bahwa bahan ajar yang dikembangakn ada perbedaan dengan bahan ajar yang sudah ada dan menarik untuk digunakan dalam proses pembelajaran. Sebagaimana terlihat dari hasil rekapitulasi respon guru dan respon siswa terhadap praktikalitas bahan ajar diperoleh hasil yaitu, hasil respon guru terhadap praktikalitas bahan ajar memperoleh persentase kepraktisan $96,43 \%$ dengan kategori sangat praktis. Hal ini menunjukkan bahwa bahan ajar yang dikembangkan sangat praktis digunakan dalam prosses pembelajaran tematik terpadu di kelas V SD serta siswa sangat terbantu dalam memahami materi melalui tahapan dalam proses pembelajaran. 


\section{Hasil analisis data respon siswa terhadap bahan ajar}

Hasil analisis terhadap angket respon siswa memperoleh nilai rata-rata secara keseluruhan 84,5 dengan kategori praktis. Menurut siswa bahan ajar yang digunakan memiliki tampilan yang menarik. Bahan ajar juga mampu meningkatkan keaktifan rasa ingin tahu siswa untuk bekerjasama dengan baik. Gambar-gambar yang asli dan komunikatif juga mampu meningkatkan motivasi siswa. Respon baik juga terlihat pada akhir pembelajaran. Beberapa siswa masih berharap masih ada pertemuan berikutnya dengan menggunakan bahan ajar menggunakan model Discovery Learning ini. Hal ini menunjukkan bahwa siswa senang menggunakan bahan ajar ini.

Dari hasil repon guru dan siswa di atas dapat disimpulkan bahwa bahan ajar yang dikembangkan sudah praktis sehingga memudahkan guru untuk mengajarkan materi pada siswa, kemudian bahan ajar juga memudahkan guru untuk menarik minat siswa dalam pembelajaran. Selain itu bahan ajar menurut siswa memiliki tampilan yang menarik, mudah dipahami, membuat siswa aktif selama pembelajaran. Hal ini sesuai dengan pendapat Plomp (2007:127) "Sebuah bahan ajar dikatakn praktis apabila bahan ajar tersebut dapat digunakan dengan mudah oleh guru dan siswa dalam pembelajaran.

\section{Hasil wawancara terhadap praktikalitas bahan ajar}

Hasil analisis berdasarkan hasil wawancara guru dan siswa setelah proses pembelajaran berlangsung memperoleh respon yang positif. Berdasarkan wawancara dengan guru dan siswa memberi penjelasan bahwa bahan ajar yang dikembangkan dapat membantu guru dalam proses pembelajaran. Sedangkan hasil wawancara dengan siswa diperoleh penjelasan bahwa siswa senang dan mudah menggunakan bahan yang dikembangkan. Hal ini terlihat dari beberapa siswa yang diwawancarai. Menurut mereka bahan ajar yang digunakan memiliki tampilan yang menarik. Bahan ajar mampu meningkatkan keaktifan siswa untuk bekerja sama dengan baik. Gambar-gambar yang terdapat dalam bahar juga mapu meningkatkan rasa ingin tahu dan memotivasi siswa. Sesuai menurut Prastowo (2014:142) menjelaskan bahwa "Bahan ajar tematik harus memunculkan berbagai karakteristik dasar pembelajaran tematik yaitu: pertama, menstimulus siswa agar aktif; kedua, menciptakan suasana pembelajaran yang menyenangkan (joyful learning); ketiga, menyuguhkan pengetahuan yang holistik (tematik); dan keempat, memberikan pengalaman langsung (direct experiences)". Dengan demikian dapat disimpulkan bahwa bahan ajar yang telah dikembangkan praktis digunakan di kelas V SD.

Berdasarkan hasil dan pembahasan yang dilakukan sebelumnya diperoleh bahwa bahan ajar tematik terpadu menggunakan model discovery learning di sekolah dasar sangat valid, praktis, dan efektif. Temuan ini sekaligus membuktikan bahwa bahan ajar kurikulum 2013 perlu dikembangan. Salah satu alternatifnya menggunakan model discovery learning dan disesuaikan dengan tuntutan zaman revolusi industri 4.0, serta mengakomodasi pembelajaran abad 21, seperti yang dikemukakan oleh Alismail \& McGuire, 2015, bahwa "Today, curriculum and educational decisions should be reviewed and redesigned to integrate future skills explicitly. In the 21st century curriculum, educators must integrate over 75\% of future skills" (Milestones for Improving Learning and Education [MILE], 2002) dalam (Alismail \& McGuire, 2015).

\section{Kesimpulan}

Penelitian pengembangan bahan ajar ini menghasilkan produk bahan ajar tematik terpadu menggunakan model Discovery Learning. Pengembangan bahan ajar ini divalidasikan kepada ahli kebahasan bahan ajar, kegrafikan bahan ajar, dan penyajian serta langkah-langkah model Discovery Learning yang ada pada bahan ajar. Hasil validasi dari semua ahli menunjukan bahwa pengembahan bahan ajar tematik terpadu menggunakan model Discovery Learning di kelas V SD ini valid/layak digunakan dalam proses pembelajaran. Hal ini dibuktikan dengan hasil validasi bahan ajar secara keseluruhan dengan nilai rata-rata 3,36 dengan kategori valid. Pengembangan bahan ajar ini juga diuji praktikalitas yang diujicobakan di kelas VC SDN 15 Ulu Gadut. Berdasarkan hasil uji praktikalitas yang dilakukan bahan ajar sudah praktis digunakan. Hal ini dibuktikan hasil respon guru terhadapat praktikalitas bahan ajar memperoleh persentase kepraktisan 96,43\% dengan kategori sangat praktis. Sedangkan hasil dari respon siswa memperoleh hasil dengan persentase kepraktisan $85,5 \%$ dengan katagori praktis. Kemudian berdasarkan hasil wawancara dengan siswa yang peneliti lakukan dengan wawancara terstruktur, secara umum hasil wawancara yang peneliti dapatkan bahwa bahan ajar menarik dan mudah dipahami oleh siswa. 


\section{Referensi}

Alismail, H. A., \& McGuire, P. (2015). 21 St Century Standards and Curriculum: Current Research and Practice. Journal of Education and Practice, 6(6), 150-155.

Amiyani, R., \& Widjajanti, J. B. (2019). Self-confidence and mathematics achievement using guided discovery learning in scientific approach. In Journal of Physics: Conference Series (Vol. 1157). https://doi.org/10.1088/1742-6596/1157/4/042093

Arikunto, S. (2009). Dasar-dasar Evaluasi Pendidikan. Jakarta: Bumi Aksara.

Barrett, P., Gaskins, J., \& Haug, J. (2019). Higher education under fire: implementing and assessing a culture change for sustainment. Journal of Organizational Change Management, 32(1), 164-180. https://doi.org/10.1108/JOCM-04-2018-0098

Bequette, M., Cardiel, C. L. B., Cohn, S., Kollmann, E. K., \& Lawrenz, F. (2019). Evaluation Capacity Building for Informal STEM Education: Working for Success Across the Field. New Directions for Evaluation, 2019(161), 107-123. https://doi.org/10.1002/ev.20351

Capuano, N., \& Toti, D. (2019). Experimentation of a smart learning system for law based on knowledge discovery and cognitive computing. Computers in Human Behavior, 92, 459-467. https://doi.org/10.1016/j.chb.2018.03.034

Cheng, S.-F. (2018). Application of Creative Teaching. Hu Li Za Zhi The Journal of Nursing, 65(6), 4. https://doi.org/10.6224/JN.201812_65(6).01

Desyandri. (2011). Peningkatan Pembelajaran Seni Musik Berbasis Pendidikan Budaya dan Karakter Bangsa di Pendidikan Dasar. In Seminar Internasional Etnik Serumpun Indonesia-Malaysia.

Desyandri. (2012). The Usage of CTL Approach to Improve the Process and Learning of Singing to Studen Class III Elementary School. Jurnal Pedagogi FIP UNP.

Desyandri; Vernanda, D. (2017). Pengembangan bahan ajar tematik terpadu di kelas $\mathrm{v}$ sekolah dasar menggunakan identifikasi masalah Desyandri. In Seminar Nasional HDPGSDI Wilayah 4 (pp. 163174).

Faisal. (2014). Sukses Mengawali Kurikulum 2013 di SD.Yogyakarta: Diandra Creative.

Hernawan, A. H. (2009). Pengembangan Model Pembelajaran Tematik di Kelas Awal Sekolah Dasar. Makalah.

Hosnan. (2014). Pendekatan Saintifik dan Konseptual dalam Pembelajaran Abad 21. Jakarta: Ghalia Indonesia

Kobayashi, K. (2019). Interactivity: A potential determinant of learning by preparing to teach and teaching. Frontiers in Psychology, 9(JAN). https://doi.org/10.3389/fpsyg.2018.02755

Kung, F.-W. (2019). Teaching second language reading comprehension: the effects of classroom materials and reading strategy use. Innovation in Language Learning and Teaching, 13(1), 93-104. https://doi.org/10.1080/17501229.2017.1364252

Kurniasih, I dan Sani, B. (2014). Implementasi Kurikulum 2013 Konsep dan Penerapan. Surabaya: Kata Pena.

Lenk, T., Glinka, P., \& Hesse, M. (2019). Educational Federalism in Germany-Financial Evaluation of the Constitutional Law Amendment. Wirtschaftsdienst, 99(3), 196-202. https://doi.org/10.1007/s10273019-2418-8

Machali, I. (2014). Kebijakan perubahan kurikulum 2013 dalam menyongsong Indonesia emas tahun 2045. Jurnal Pendidikan Islam, 3(1), 71-94.

Malsbary, C. B. (2018). Teachers as Creative Designers in Transnationalism. Urban Education, 53(10), 1238-1264. https://doi.org/10.1177/0042085915613548

Muslich, M. (2010). Text Book Writing. Jogjakarta: Ar-Ruzz Media Group

Plom, T. Dan Nieveen, N. (Eds). (2017). An Introduction to Educational Design Research. Enschede: SLO (Netherlands institute for curriculum development).

Prastowo, A. (2014). Pengembangan Bahan Ajar Tematik: Tinjauan Teoretis dan Praktis. Jogjakarta: DIVA Press.

Priatna, N., Martadipura, B. A. P., \& Lorenzia, S. (2019). Development of mathematic's teaching materials using project-based learning integrated STEM. In Journal of Physics: Conference Series (Vol. 1157). https://doi.org/10.1088/1742-6596/1157/4/042006

Riyanto,Y. (2010). Paradigma Baru Pembelajaran: Sebagai Referensi Bagi Pendidik dalam Implementasi Pembelajaran yang Efektif dan Berkualitas. Surabaya: Prenada Media.

Ridwan \& Sunarto. (2007). Pengantar Statistik Untuk Penelitian: Pendidikan, Sosial, Komunikasi, Ekonomi dan Bisnis. Bandung: Alfabeta.

Saputri, A. T. W. (2017). Pengembangan Desain Pembelajaran Tematik Integratif Berbasis Pendekatan 
Contextual Teaching and Learning (CTL) Kelas 4 Sekolah Dasar. Program Studi Pendidikan Guru Sekolah Dasar FKIP-UKSW.

Siregar, Sy. (2011). Statistika Deskriptif untuk Penelitan. Jakarta: Raja Grafindo Persada

Sukerti, N. N., Marhaeni, A. A. I. N., \& Suarni, N. K. (2015). Pengaruh Pembelajaran Tematik Terpadu melalui Pendekatan Saintifik terhadap Minat Belajar dan Hasil Belajar Siswa Kelas IV SD Negeri 2 Tibubeneng Kuta Utara. PENDASI: Jurnal Pendidikan Dasar Indonesia, 4(1).

Syarafina, D. N., \& Mahmudi, A. (2019). The effect of guided discovery learning on student self-efficacy. In Journal of Physics: Conference Series (Vol. 1157). https://doi.org/10.1088/17426596/1157/4/042095

Teplykh, M. S., Akhmetzyanova, M. P., \& Bashirova, T. A. (2019). Problematization as an innovative form of philosophy teaching. Perspektivy Nauki I Obrazovania, 37(1), 120-134. https://doi.org/10.32744/pse.2019.1.9 